\title{
A face de incentivo à leitura em redes sociais:
}

\section{um relato de experiência}

The face to encourage reading in social networks:

\author{
an experience reports
}

Fomentar la lectura en las redes sociales:

un informe de experiencia

\section{Cyndi Moura Guimarães}

Instituto Federal de Sergipe (IFS), Aracajú/SE - Brasil

Elza Ferreira Santos

Instituto Federal de Sergipe (IFS), Aracajú/SE - Brasil

Sônia Pinto de Albuquerque Melo

Instituto Federal de Sergipe (IFS), Aracajú/SE - Brasil

\section{Resumo}

Este artigo faz parte de um trabalho sobre o incentivo à leitura em tempos de tecnologia digital. O texto examina questões relativas ao uso do Facebook na educação, baseado em um estudo da utilização da plataforma em um contexto educacional específico: o incentivo à leitura. Com base em dados coletados junto a um grupo de 36 participantes, em uma pesquisa-ação, o artigo discute questões pertinentes ao uso de redes sociais no contexto educacional e a utilização do Facebook como ferramenta de incentivo à leitura. Sugere-se que as redes sociais podem oferecer possibilidades bastante interessantes para a educação e propor muitos desafios às práticas e concepções correntes.

Palavras-chave: Leitura, Redes sociais, Ensino, Facebook

\section{Abstract}

This article is part of a work on encouraging reading in times of digital technology. The text examines issues related to the use of Facebook in Education. It is based on a study about using of this platform in a specific educational context: encouraging reading. From data collected with a group of thirty-six participants in action research, the article discusses relevant issues about the use of social networks in educational context and the use of Facebook as a tool to encourage reading. The research suggests that social networks can offer quite interesting possibilities for education and pose many challenges to current practices and concepts.

Keywords: Reading, Social networks, Teaching, Facebook

\section{Resumen}

Este artículo es parte de un trabajo sobre el fomento de la lectura en tiempos de tecnología digital. El texto examina cuestiones relacionadas con el uso de Facebook en la educación a partir de un estudio del uso de la plataforma en un contexto educativo específico: fomentar la lectura. A partir de datos recogidos de un grupo de 36 participantes, en una investigación-acción, el artículo analiza cuestiones pertinentes sobre el uso de las redes sociales en el contexto educativo y el uso de Facebook como herramienta para fomentar la lectura. Se sugiere que las redes sociales pueden ofrecer posibilidades bastante 
interesantes para la educación y plantear muchos desafíos a las prácticas y conceptos actuales.

Palabras clave: Lectura, Redes sociales, Enseñanza, Facebook.

\section{Introdução}

$\mathrm{Na}$ sociedade atual, a inserção das tecnologias digitais na vida das pessoas tem provocado grandes mudanças nas formas de interação e comunicação. Uma dessas consequências, observada por meio da prática de leitura, foi o surgimento de textos híbridos que associam imagens, sons, ícones, links, alterando assim o comportamento do leitor quanto ao processamento de informações e à construção de significados.

As Tecnologias da Informação e Comunicação (TIC) estão presentes no universo social e trazem para a educação uma importante responsabilidade na formação de leitores, afinal "as escolas precisam preparar os alunos também para o letramento digital, com formas de pensar e com competências diferentes da era do impresso" (ZACHARIAS, 2016, p. 17), promovendo mudanças na forma de ensinar a leitura e as práticas de sala de aula, visando à formação de leitores para o universo midiático.

Para Mey (1998), o letramento não se restringe às habilidades de ler, escrever e navegar na internet. É essencial conhecer as razões e a finalidade dos conhecimentos que se buscam, a fim de serem significativos. Segundo o autor, "é necessário também que se saiba o quê se procurar na rede" (MEY, 1998, p. 333).

Soares (2002), por sua vez, ressalta a importância de refinar o conceito de letramento, dada a atual conjuntura, que requer da sociedade a inserção "de novas e incipientes modalidades de práticas sociais de leitura e de escrita, propiciadas pelas recentes tecnologias de comunicação eletrônica - 0 computador, a rede (a web), a Internet" (SOARES, 2020, p. 146).

Nessa perspectiva, as práticas de leitura e de escrita oportunizadas pelos recursos tecnológicos viabilizaram mudanças significativas no modo de vida, e, diante de tal dinâmica, os mediadores de leitura devem refletir como os novos suportes podem contribuir para retirar do país os números decepcionantes referentes à leitura. Afinal, formas e veículos diferenciados se transformam em poderosos aliados do processo de formação de leitores. 
"A quantidade de textos em circulação, bem como a leitura, tem aumentado em vez de diminuir" (MARTHA; VALARINI, 2015, n.p.) ${ }^{1}$. A facilidade com que são colocados em circulação incentiva a produção e a leitura de textos, veiculados em suporte tradicional ou em e-book, blog, Facebook, entre outros. Mas que tipo de leitura estamos mesmo fazendo? De que modo essa leitura se configura em sala de aula?

Propõe-se, pois, neste texto, refletir sobre a aplicabilidade pedagógica de uma rede social como o Facebook, a fim de promover não só a leitura, mas também a produção de sentidos aos textos lidos e aos textos produzidos como consequência de uma leitura crítica. Ver-se-ão, por meio do Facebook, possibilidades e potencialidades de incentivo à leitura e à escrita dentro de uma perspectiva de uma educação integrada.

\section{Redes sociais no contexto educacional}

O uso de redes sociais como forma de comunicação trouxe transformações no processo de criação e recepção de textos, uma vez que apresentam aspectos como hipertextualidade e interatividade, que demandam habilidades de leituras e de produções específicas. Assim, segundo Zacharias (2016, p. 21), é possível entender o novo leitor que está surgindo com a multiplicidade de textos e mensagens da comunicação em rede.

As ferramentas de interação permitem ao novo leitor selecionar 0 conteúdo de acordo com seu interesse, assim como opinar, comentar e se sentir integrado no contexto. E essa interatividade não se limita à técnica da leitura, mas, sobretudo, à maneira como os indivíduos se relacionam, aprendem e acessam a informação.

Mesmo com todas as possibilidades das tecnologias, a leitura literária esbarra em alguns obstáculos que devem ser superados. Afinal, é necessário incluir no contexto escolar uma pedagogia que valorize o universo multimidiático dos ambientes digitais e que não se restrinja à cultura do impresso.

Além de um espírito mais aberto quanto aos gêneros e às modalidades de leitura, todos aqueles que hoje se dedicam à educação devem estar preparados para as novas tecnologias. E talvez seja a leitura do texto literário dirigido a crianças e jovens a atividade que mantenha relações mais peculiares com as perspectivas dos novos suportes, já que se identifica de forma mais direta com o lúdico e com

${ }^{1}$ A obra está disponível na Biblioteca Virtual Pearson e não disponibiliza a numeração das páginas, impossibilitando indicar a respectiva referência.

Revista Educação Online, Rio de Janeiro, n. 38, set-dez 2021, p. 300-314 
a descoberta. Entretanto, a questão não parece ser tão simples assim para aqueles que se envolvem de alguma maneira com a mediação dessa produção, pois grande parte dos mediadores considera que a leitura do texto literário deve se concretizar, sobretudo, a partir do contato físico com o livro. (MARTHA; VALARINI, 2015, s. p.)

O professor enfrenta desafios e novas possibilidades cada vez maiores no processo de ensino-aprendizagem, e as redes eletrônicas não trarão a solução para modificar profundamente a relação pedagógica, mas poderão facilitar a pesquisa, a interação e o diálogo entre professores e alunos. A relação "aluno-internet" precisa transpor os limites da rede e chegar à sala de aula, para que o professor utilize os resultados dessa relação para o avanço do seu trabalho; afinal, o sistema tradicional não deixa de existir, ao contrário, pode ter no ciberespaço um aliado, quando partilha e leva a outras leituras.

A inclusão do universo digital nas práticas educacionais não implica na exclusão do impresso, e sim uma articulação. No entanto, o professor precisa refletir sobre essa integração para poder explorar de forma eficiente o potencial dos dois universos.

É possível trabalhar com textos no ambiente digital através da leitura e navegação em sites, blogs, redes sociais, explorando suas potencialidades e usabilidade, valorizando as outras linguagens agregadas aos textos verbais. Nesse texto, o ambiente digital far-se-á presente através do uso de ferramentas e aplicativos propostos em uma atividade didática e serão de grande importância para levar a leitura através do universo digital.

A tela como espaço de escrita e de leitura traz não apenas novas formas de acesso à informação, mas também novos processos cognitivos, novas formas de conhecimentos, novas maneiras de ler e de escrever, enfim, um novo letramento, isto é, um novo estado ou condição para aqueles que exercem práticas de escrita e de leitura na tela. (SOARES, 2002, p.152)

Para incluir o letramento digital nas escolas, é importante equipar as salas de aulas com recursos tecnológicos, mas isso não é suficiente. É preciso repensar os ambientes de aprendizagem, assim como somar os novos comportamentos do leitor às práticas habituais de leitura, utilizando textos de diferentes mídias, levando em conta as novas formas de organizar os saberes, investindo no letramento. Conforme explica Kirchof, (2016, p. 208), "A formação de leitores capazes de se apropriarem das novas textualidades produzidas e disponibilizadas no universo digital demanda um investimento em múltiplos 
letramentos, os quais deverão abarcar variadas práticas e usos que envolvem tais fenômenos".

Segundo Zacharias (2016, p. 26), "incluir inovações nas instituições de ensino não é uma tarefa fácil, visto que a estrutura e organização que prevalecem nas escolas preservam modelos do século passado"; além disso, ainda hoje, nem todas as escolas e professores dispõem dos recursos desejáveis, sejam materiais ou imateriais, para desenvolver o letramento digital dos alunos. Ainda assim, o mais importante não é a inclusão de várias mídias, linguagem e textos do mundo digital, e sim a promoção de condições para formas de leituras plurais, com concepções de ensino e de aprendizagem que tenham o aluno como protagonista, a fim de diminuir a distância entre as leituras e as práticas que se desenvolvem fora da escola e as que são privilegiadas por ela.

A escola deve colaborar para o desenvolvimento de competências necessárias, para que os alunos possam atuar de maneira efetiva na sociedade da informação e comunicação. O letramento digital vai além de apresentar gêneros que circulam nas mídias digitais ou ensinar a lidar com dispositivos e ferramentas. A leitura no ambiente digital permite usar a informação de maneira criativa e inovadora para desenvolver novas ideias, e a escola deve contribuir, ao ensinar a controlar os propósitos de leitura literária ou não, de buscar, selecionar, interpretar e contrastar informações. Assim, Moreira e Januário (2014) justificam:

De fato, o sistema educativo e o subsistema social da aprendizagem não podem ser entendidos como alheios aos (novos) processos produtivos dos (novos) processos sociais. Inevitavelmente, a nova cultura em rede estende-se ao sistema de ensino, e, em paralelo ao que foi dito quanto à estrutura (aprendizagem responsável, ao longo da vida para garantir a adaptabilidade e flexibilidade exigidas), a extensão das redes como processo e meio educativos equivalerá a integrar no quotidiano dos indivíduos os próprios processos de aprendizagem. (MOREIRA; JANUARIO, 2014, p.73)

Segundo Torres, Fialho e Shimazaki (2014, p. 350), devido à popularização do uso de redes sociais, evidencia-se a repercussão desse canal de informação entre os estudantes de modo geral. Por essa via, o professor pode compartilhar experiências com seus alunos, promovendo discussões sobre temas relevantes da comunidade escolar e desenvolvendo projetos de intervenção com ações interdisciplinares. Assim, surge a necessidade de se refletir sobre o papel do professor nesse espaço comunicacional como mediador 
do processo educativo, levando em consideração a sensibilização do trabalho em rede que é voltado para a coletividade, a colaboração e a partilha.

As redes sociais são parte integrante da vida dos nossos estudantes e entre elas, destaca-se o Facebook, uma das mais utilizadas em todo o mundo como espaço de partilha, de interação e de discussão de ideias, e que também pode ser utilizada como ferramenta de incentivo à leitura. Por essa razão, esse foi o instrumento adotado para o desenvolvimento deste estudo.

\section{Redes sociais como ferramenta de incentivo à leitura}

Os avanços das tecnologias de informação e da comunicação têm estimulado de forma decisiva a aprendizagem, para além das estruturas educativas formais, assim, embora não se centrando no desenvolvimento de aprendizagens formais, as redes sociais podem constituir um espaço importante para a aprendizagem informal e cultural.

Com o objetivo de incentivar a leitura entre 36 jovens estudantes do ensino médio integrado ao técnico de aquicultura do Instituto Federal de Sergipe - Campus Estância, foi aplicada uma atividade utilizando como ferramenta o Facebook. Foi criado um grupo aberto no perfil do Facebook do Campus Estância, chamado "Lendo no IFS"2, com o objetivo de incentivar a leitura e registrar impressões de leituras, pois, além do mural, essa rede social dispõe ainda de outros recursos que podem ter aplicabilidade pedagógica como: os Grupos que são espaços on-line, criados com um objetivo/interesse particular e que podem ser úteis para estudantes e professores trabalharem de forma colaborativa.

Os grupos do Facebook se caracterizam como uma área disponível na interface em que um usuário (discente ou docente) poderá criar no momento em que achar necessário. Os membros de um grupo não são necessariamente uns amigos do outro (ou que exista conexão anterior entre eles), o que possibilita uma troca de conhecimentos entre pessoas sem links na rede e a formação de novas conexões em suas redes. Dentre as características de um grupo no Facebook, o mesmo poderá ser do tipo: Aberto, tanto o grupo, os participantes, como as publicações deste grupo, estão visíveis e o mesmo poderá ser achado na busca do Facebook; Fechado, o grupo e os participantes estão visíveis, mas quem não faz parte do grupo não pode visualizar as publicações. (CHAGAS; LINHARES, 2014, p. 299)

2Disponível em: https://www.facebook.com/groups/137856230500819/. Acesso em: 20 mar. 2019.

Revista Educação Online, Rio de Janeiro, n. 38, set-dez 2021, p. 300-314 
Válido se faz lembrar que o Grupo "Lendo no IFS" pôde ser criado no perfil oficial da página do Campus, diante do consentimento da Direção Geral, que compreendeu ser um canal de comunicação e incentivo contínuo. Também foi mantido o acesso como "aberto", para que qualquer interessado pudesse acompanhar o grupo, mesmo que não fosse membro da turma participante da pesquisa.

Além de imagens de incentivo à leitura, também foi postado o vídeo do Youtube do canal "Ler antes de Morrer" (2015), com comentários sobre o livro "A menina que roubava livros". O objetivo era exemplificar o uso de outra ferramenta tecnológica para estimular a leitura, a análise crítica sobre obras e estimular a produção de seus próprios vídeos sobre suas leituras para serem publicados na fanpage.

A proposta inicial da atividade era a leitura de livros. No entanto, como naquele momento, os alunos estavam participando de várias atividades escolares, a exemplo de feira de ciências, visitas técnicas, provas, o tempo se tornou limitado. Assim, propôs-se a leitura de textos curtos, como contos, minicontos, capítulos de livros, artigos científicos e artigos de opinião. Nesse sentido, foi dado o direito aos alunos de escolherem que texto gostariam de ler.

Essa etapa de apresentação dos textos e da escolha para leitura aconteceu em parceria com o professor de inglês, com a professora de química, com a turma e com as pesquisadoras. Era fundamental que houvesse a participação de docentes diversos. Os textos foram indicados pela pesquisadora e pelos professores supracitados. Conforme Solé (2014), o trabalho de leitura deve ser estendido ao longo de toda a escolaridade, e o prazer de ler pode e deve ser ensinado por todos os professores, afinal, a partir do ensino médio, espera-se que os jovens melhorem sua habilidade e, progressivamente, se familiarizem com a literatura, adquirindo, de fato, o hábito da leitura.

A turma foi dividida em grupos de cinco estudantes. Cada grupo escolheu um texto para ler. Feita a leitura coletivamente, foi sugerido que eles produzissem um texto. A concepção de texto foi, nesse momento, ampliada: verbal e não verbal. Os grupos produziram fotografias, vídeos, poemas e análises. Toda essa produção compôs, posteriormente, as postagens do grupo do Facebook, segundo os critérios apresentados. 
No início da atividade, foram apresentadas as regras e critérios para compor as postagens no Facebook, a saber: participar do grupo "Lendo no IFS", no Facebook do IFS Campus Estância; escolher uma das leituras sugeridas por grupo; fazer uma postagem sobre a leitura realizada no grupo do Facebook e comentar a postagem feita por seus colegas, a fim de gerar interatividade e criticidade.

Como a rede social não foi criada com objetivos educativos, o desafio foi aproveitar o Facebook para construir novos ambientes de aprendizagem estimulantes e prazerosos, consequentemente, lúdico-pedagógicos. Para isso,

os professores precisaram otimizar a rede, promovendo uma forma de aprender com objetivos bem delineados, metodologias e avaliações bem claras e coerentes com os princípios de uma aprendizagem que se deseja colaborativa e construtivista. (MOREIRA; JANUARIO, 2014, p. 75)

O professor, ao utilizar o Facebook no processo de ensino e aprendizagem, precisa estabelecer regras claras aos alunos para que não ocorram conflitos e dificuldades durante a sua utilização. É importante que o professor organize e planeje suas aulas e esclareça todas as ações que envolvem a utilização dessa rede social. (MATOS; FERREIRA, 2014, p. 396)

Os critérios para avaliar a postagem levaram em conta conteúdo, originalidade e interatividade. A esses critérios, estavam associados: cor, poeticidade, brilho, adequação linguística de acordo com as variantes social, econômica e regional, por exemplo.

As sugestões de leitura foram: capítulo 18 do livro O perfume (1985) de Patrick Süskind; a literatura de cordel Tabela e Cia (OLIVEIRA et al. 2016, p. 7); os contos "Beijos e abraços", de Luís Fernando Veríssimo; "Aula de inglês", de Rubem Braga; "O arquivo", de Victor Giudice; "As Marias", de Dalton Trevisan; "Felicidade clandestina", de Clarice Lispector; "Mar", de Rubem Braga; "Jeito de matar lagartas", de Antônio Carlos Viana; e "Venha ver o pôr do sol", de Lygia Fagundes Telles; o artigo de revista "O mundo maravilhoso da palavra intraduzível", de Edgar Murano; e um artigo científico ${ }^{3}$ sobre o efeito do ph da água no equilíbrio iônico de alevinos.

\footnotetext{
${ }^{3}$ Referência do artigo: NASCIMENTO, T. S. R. BOIJINK; C. de L. PÁDUA, D. M. C.Efeito do pH da água no equilíbrio iônico de alevinos de Piaractusmesopotamicus. In: CONGRESSO BRASILEIRO DE PRODUÇÃO DE PEIXES NATIVOS DE ÁGUA DOCE. 1., Dourados, MS, 2007. Disponível em: https://ainfo.cnptia.embrapa.br/digital/bitstream/item/115054/1/QAGUA06.pdf. Acesso em: 20 mar. 2019.
} 
Os alunos escolheram os textos, leram e produziram as imagens e vídeos no horário de aulas. Depois, eles mesmos publicaram suas produções no grupo do Facebook.

As produções foram avaliadas pelas pesquisadoras e pelos professores de química e de inglês, através de uma tabela de critérios, que foi compartilhada on-line através de Planilhas Google. Não foram avaliações para gerar notas necessariamente, mas prioritariamente conceitos. As produções foram surpreendentes e criativas, apesar do curto tempo em que foram elaboradas, visto que estavam participando de outras atividades pedagógicas inerentes ao ano letivo que cursavam.

\section{As impressões de leitura no Facebook}

O grupo 1 escolheu o conto "As Marias", de Dalton Trevisan. O conto reproduz a história de uma mulher pobre, sofrida, explorada, que deposita na figura masculina do militar a esperança de uma vida melhor. Apaixonada, acredita nas promessas do cabo, engravida e é abandonada. E assim, repetese a história estigmatizada pelas mulheres sem identidade, anuladas em sua condição social, sem recursos para mudar o rumo de suas histórias, conforme texto postado pelos alunos:

Nela retrata a vida de uma empregada que teve sua filha e por não ter condições de criá-la deu para sua patroa, e, contudo, sua filha teve a mesma profissão que ela. A principal crítica dessa obra é em relação ao determinismo social que enfatiza o fato de que se a mãe foi empregada, a filha tem que ter a mesma profissão e futuramente a sua primogênita. Também fala sobre o preconceito com as empregadas domésticas, que não podem conviver no mesmo ambiente que os seus patrões. (FACEBOOK, 2018)

Os alunos fotografaram uma colaboradora do Campus varrendo o prédio escolar. Com o consentimento dela, pretenderam mostrar que, ainda hoje, no Brasil, muitas pessoas discriminam o trabalho braçal, que, associado à limpeza, é executado predominantemente por mulheres e remunerado de modo precário. Na descrição, falaram sobre o conteúdo do conto e nos comentários, portanto, fizeram reflexões. Os avaliadores também comentaram e teceram elogios:

Nossa que INCRÍVEL!!! Tudo que uma sociedade aproveitadora precisava ouvir e ver o que ela mesmo faz com seu povo, menospreza uma mulher ou até mesmo um homem pela sua origem ou pelo status social. Quantas famílias não são representadas nesse texto? Famílias carentes, com uma mãe ou um pai que sofre chantagem pelo seu patrão ou patroa. (FACEBOOK, 2018) 
O grupo 2 optou pelo conto "Felicidade Clandestina", de Clarice Lispector. Nele, a narradora, em primeira pessoa, conta suas primeiras experiências com um livro. Porém, esse livro é de uma menina travessa, que o oferece emprestado para a narradora, mas sempre inventa uma desculpa para não entregar o livro a ela. Até que a mãe da menina travessa descobre isso e entrega o livro para a narradora, que passa a saborear o livro como se fosse um amante.

Eles postaram uma fotografia com três alunas retratando a cena em que a menina é obrigada a entregar o livro. Nessa postagem, fizeram apenas uma simples descrição, e seus comentários foram pouco reflexivos. Os avaliadores Ihes mostraram o quanto ainda precisavam compreender os aspectos metafóricos que aquela leitura lhes impunha:

Uma garota ruiva gorda e metida que tem o pai como dono de livraria, tira o proveito de uma menina que não tem oportunidade de ler livros, enganando dizendo que iria emprestar o mesmo, mas sempre a engana dizendo que estar com outra pessoa, até que um dia sua mãe boazinha obriga a filha a dar o tão querido livro para a menina que espera por tanto tempo. Esse livro tem o objetivo de incentivar a leitura e mostrar que a paixão pela leitura é uma verdadeira felicidade. E o quanto é bom a leitura no nosso dia a dia! (FACEBOOK, 2018)

O grupo 3 escolheu o conto "Venha ver o pôr do sol", de Lygia Fagundes Telles. Esse conto foi inserido nas opções para fazer referência ao evento de Halloween, que iria acontecer no Campus, naquele mesmo dia da atividade, o que despertou o interesse de mais de um grupo, sendo necessário definir, através de um amigável jogo de "par ou ímpar", qual deles o leria.

$O$ conto fala de um encontro entre ex-namorados em um cemitério, e o final da história fica aberto ao mistério típico atribuído por Telles aos seus contos, sem deixar exatamente claro o que aconteceu, por que aconteceu, qual foi a motivação do que aconteceu. Assim, o grupo criou uma foto, simulando um túmulo, e os alunos fizeram comentários que destacam o final do conto como trágico, aproximando-o da realidade:

O final do conto é trágico, Ricardo se afasta cada vez mais do local do crime até ouvir ao longe a voz de Raquel.

Isso pode acontecer tanto na vida real quanto no conto. O que reflete é que acontecem muitos casos como esse e o final é terminado em tragédia. (FACEBOOK, 2018) 
Durante a discussão sobre o conto, o grupo levantou muitas hipóteses, como a dúvida se a personagem realmente havia morrido, se não havia sido uma brincadeira e concluíram que se tratava de um feminicídio.

Os estudantes do grupo 4 escolheram o texto de artigo de revista "O mundo maravilhoso da palavra intraduzível", de Edgar Murano, que foi indicado pelo professor de inglês. O texto fala sobre algumas particularidades da língua, no que concerne às abordagens diversificadas de uma mesma realidade. Por exemplo, um vocábulo da língua portuguesa, em que se usa uma só palavra, em outros idiomas, pode-se usar dois ou três. O grupo gravou um vídeo no qual os estudantes liam trechos do texto e descreviam o conteúdo: "O texto refere-se a palavras que são 'intraduzíveis' para nós, ou nossa cultura, palavras que não vemos em nosso dia a dia; no texto tem várias palavras de diferentes lugares e culturas e seus significados" (FACEBOOK, 2018).

Os membros do grupo 5 optaram pelo capítulo 18 do livro Perfume, história de um assassino, de Patrick Süsking. O livro foi publicado em 1985, e a história se situa na Paris do século XVIII. Conta a vida de um rapaz que nasceu totalmente sem cheiro, mas tem o olfato mais desenvolvido do mundo e acaba por matar vinte e seis jovens mulheres no processo da criação do perfume perfeito. O livro já foi adaptado para o cinema.

A seleção do capítulo 18 aconteceu, porque ele descreve detalhadamente o processo de destilação para criação dos perfumes e, assim, faz relação com a disciplina de química, visto que a atividade aconteceu em parceria com a professora da referida disciplina. O grupo postou uma foto de flores na grama, simulando um jardim, e, na descrição, os estudantes copiaram trechos de um texto disponibilizado na Internet sobre o livro, apresentando informações que não estavam no texto do capítulo. Infelizmente, foi precária a análise dos alunos, copiaram trechos da Internet e não fizeram nenhuma referência ao processo de destilação.

O momento foi oportuno para serem discutidas questões como plágio e o que é pesquisar na Internet. Serviu também para a professora de química pensar em como lhes mostrar o processo de destilação no laboratório. $\mathrm{Na}$ condição de avaliadoras e pesquisadoras, foi também um instante de autocrítica: Cada aluno tem seu ritmo de leitura e maturação do que foi lido. Nem todos 
produzem ao mesmo tempo. $E$ isso não pode significar que essa equipe fosse menos produtiva do que as demais.

O grupo 6 escolheu o conto "Mar", de Rubem Braga. O tema principal do texto seria o mar, como é claramente visto no título, mas não somente ele, e sim as sensações que provoca. Os alunos fizeram um pequeno vídeo de um aquário existente no Campus para simular o mar, compreenderam que o texto foca nas emoções que o mar provoca e comentaram com pequenas frases que transmitiram a ideia de composição de uma poesia, gerando comentários bastante positivos dos avaliadores.

O som que acalma a alma

As ondas que movem a vida

Um mar que deixa lembranças

Meus pensamentos vão e voltam como as ondas do mar!!!

(FACEBOOK, 2018)

O texto do grupo 7 foi analisado por uma única aluna, que preferiu desenvolver a atividade sozinha. Ela escolheu o conto "Beijos e abraços", de Luiz Fernando Veríssimo, que mostra algumas ações reveladoras de hábitos de se cumprimentar, como o ato de se beijar entre amigos. A estudante postou uma montagem de quatro fotos entre duas colegas, representando formas de cumprimento, fez uma breve análise do texto e obteve da banca avaliadora elogiosos comentários:

Os estrangeiros se cumprimentam e demonstram afeto de maneira, discreta e carinhosa. Já os brasileiros são diferentes! Eles se cumprimentam à base de abraços acompanhados de alguns tapas nas costas, murros no braço ou até mesmo alguns insultos, mas essa é a maneira de dizer - Olá como vai, senti saudades! Os estrangeiros acham que é briga, pode até ser, mas na maioria das vezes é a forma brasileira de demostrar afeto. (FACEBOOK, 2018)

O grupo 8 optou pelo conto "Aula de inglês", de Rubem Braga. O texto relata a experiência vivida pelo narrador na sua primeira aula de inglês e, com fino humor e ironia, ele capta o distanciamento entre o ensino da língua inglesa e o seu uso. Os estudantes postaram uma fotografia de uma estudante pensando sobre a palavra Ash-tray escrita no quadro. Os comentários fizeram apenas uma descrição do texto e, infelizmente, com análise precária. Apesar disso, a participação dos alunos é sempre relevante, e a pesquisa reconhece que cada equipe, cada aluno, tem um ritmo de leitura, de compreensão e de produção: 
Fala sobre uma aula de inglês que tinha uma professora que todos temiam; certo dia ela levou um objeto pra escola que fazia parte da aula e começou a perguntar o que era aquilo que ela tinha em mãos, e ninguém sabia o que era. Daí ela perguntou a um menino da sala o que era aquilo, mas parecia que ele tava vendado ou algo assim do tipo, porque ele nunca acertava o que era realmente aquilo. Mas certo momento ele tava com algumas dúvidas, mas resolveu apostar naquilo ele achava que era, ele falou e acertou era um "Ash-tray" um cinzeiro. Depois ele ficou muito contente porque já estava dominando um pouco o inglês. (FACEBOOK, 2018)

Enfim, sobre a análise da participação e produção dos oito grupos, considerando o período dedicado a essa atividade, o resultado foi positivo, pois, além de ter estimulado a atividade de leitura e de interpretação, os alunos exercitaram a criatividade, produzindo suas próprias fotos e vídeos com os recursos disponíveis no momento e dentro do espaço do IFS. Houve comentários bastante críticos e reflexivos e alguns que precisavam de mais tempo para serem amadurecidos. Entretanto, o mais importante é que todos os alunos presentes participaram, leram e comentaram na página do Facebook.

A aprendizagem não foi só dos alunos. Também professores e pesquisadoras aprenderam muito: aproximar a realidade do estudante e usar ferramentas que fazem parte do dia a dia podem fazer da leitura algo simples e prazeroso.

\section{Considerações finais}

Com as novas exigências do mundo contemporâneo, advindas da evolução tecnológica, os professores e mediadores de leitura precisam buscar novas maneiras de fazer educação e de incentivar a leitura.

Conforme Moreira e Januario (2014, p.75), se aceitarmos que os ambientes virtuais são ferramentas inovadoras para a criação de comunidades de aprendizagem, é crucial reconhecer a necessidade de uma nova perspectiva na criação de contextos de aprendizagem. Assim, perceber como se pode ensinar e aprender, formal ou informalmente, em espaços abertos e de aprendizagem colaborativa, em redes sociais na Internet, como o Facebook, é um dos grandes desafios que se colocam a todos os educadores.

A atividade com o Facebook foi uma estratégia aplicada em conjunto com outras atividades de uma sequência didática, com objetivo de incentivar a leitura e a partir de um levantamento quantitativo na biblioteca do Campus. Assim, foi 
possível observar, um mês depois, o aumento de empréstimos de livros pelos participantes e a afirmação do interesse dos estudantes em continuar participando de atividades de leitura.

Perante esses resultados, compreendemos as potencialidades educativas das redes sociais. Assim, atividades como essa podem ser facilmente adaptadas para outras redes sociais. Elas constituem um meio privilegiado para pensar, criar, comunicar e intervir sobre numerosas situações, fomentando não só a aprendizagem formal, mas também a aprendizagem informal e não formal.

Apesar de apresentar uma enorme potencialidade nos processos de aprendizagem, por outro lado, é um desafio à educação, na medida em que pode proporcionar um processo dinâmico de ensino-aprendizagem, do qual os estudantes se sentem parte integrante, possibilitando aos estudantes ações mais autônomas e responsáveis pela construção do seu próprio conhecimento.

\section{Referências bibliográficas}

CHAGAS, A; LINHARES, R. As interfaces de interação para uma aprendizagem colaborativa no Facebook. In: PORTO, C.; SANTOS, E. (Orgs.) Facebook e educação: publicar, curtir, compartilhar. Campina Grande: EDUEPB, 2014. p.293-312.

MARTHA, Alice Áurea Penteado; VALARINI, Sharlene Davantel. Leitura e escrita no ciberespaço: fanfics em sala de aula. In: MARTHA, Alice Áurea Penteado; AGUIAR, Vera Teixeira de. (Orgs.). Leitura e escrita no ciberespaço. Porto Alegre: Edipucrs, 2015. Disponível em: Biblioteca Virtual Pearson https://bv4.digitalpages.com.br/\#/. Acesso em: 15 mar.2019.

DOMINGOS, Ana Claudia Munari. O hiperleitor e o sistema literário. In: MARTHA, Alice Áurea Penteado; AGUIAR, Vera Teixeira de. (Orgs.). Leitura e escrita no ciberespaço. Porto Alegre: Edipucrs, 2015. Disponível em:

Biblioteca Virtual Pearson https://bv4.digitalpages.com.br/\#/. Acesso em: 15 mar.2019.

KIRCHOF, Edgar Roberto. Como ler os textos literários na era da cultura digital?. Literatura e Novas Mídias. Estudos de Literatura Brasileira Contemporânea, n.47, Brasília, 2016. Disponível em: https://doi.org/10.1590/2316-40184710. Acesso em: 20 mar. 2019.

MATOS, E.; FERREIRA, J. A utilização da rede social Facebook no processo de ensino e aprendizagem na universidade. In: PORTO, C.; SANTOS, E.

(Orgs.) Facebook e educação: publicar, curtir, compartilhar. Campina Grande: Eduepb, 2014. p.387-402. 
MEY, Jacob L. As vozes da sociedade: letramento, consciência e poder. DELTA, São Paulo, v.14, n. 2, p. 331-338. 1998. Disponível em: https://www.scielo.br/j/delta/a/fvJpL89hFzkyW3wzXWzgWtD/abstract/?lang=pt . Acesso em: 20 mar. 2019.

MOREIRA, J. ; JUNUÁRIO, Susana. Redes sociais e educação: reflexões acerca do Facebook enquanto espaço de aprendizagem. In: PORTO, C.; SANTOS, E. (Orgs.) Facebook e educação: publicar, curtir, compartilhar. Campina Grande: Eduepb, 2014. p.67-84.

SOARES, Magda. Novas práticas de leitura e escrita: letramento na cibercultura. Educação e Sociedade, Campinas, n.23 , p.143-160, 2002. Disponível em: https://doi.org/10.1590/S0101-73302002008100008. Acesso em: 15 mar. 2019.

SOLÉ, Isabel. Estratégias de leitura. $6^{\underline{a}}$ ed. Porto Alegre: Penso, 2014.

TORRES, P.; FIALHO, N.; SHIMAZAKI, N. A face educacional do Facebook: um relato de experiência. In: PORTO, C.; SANTOS, E. (Orgs.) Facebook e educação: publicar, curtir, compartilhar. Campina Grande: Eduepb, 2014. p.349-364.

ZACHARIAS, Valeria R. de C. Letramento digital: desafios e possibilidades para o ensino. In: COSCARELLI, Carla Viana (Org.) Tecnologias para aprender. São Paulo: Parábola Editorial, 2016. p.16-29. 